\title{
Effects of metabolic syndrome on blood cells to Wistar rats
}

\begin{abstract}
This investigation is concentrated on how hematological markers would change in pig fat induced metabolism syndrome (MS) in adult Wistar rats. The objective of the current work was to examine the effect of diet-induced metabolic syndrome on hematological parameters. Metabolic syndrome was induced by feeding rats with diet supplemented to $10 \%$ (LF group) and 30\% (HF group) pig fat and the control rats were fed normal diet (ND) for 9 weeks. After the study period, White Blood Cell (WBC), Red Blood Cell (RBC), hematocrit (HCT), Hemoglobin, platelet (PLT), lymphocytes, monocytes, Neutrophils, Mean Corpuscular Hemoglobin Concentration (MCHC), Mean Corpuscular Volume $(\mathrm{MCV})$ were measured using BC-30s hematology analyzer.
\end{abstract}

The results showed that hematocrit, $\mathrm{RBC}$ and hemoglobin levels were significantly decreased in metabolic syndrome than in control rats respectively (37.24 \pm 10.3 vs $33.16 \pm 9.5 \%$; $7.08 \pm 3.2$ vs $6.63 \pm 2.8 \times 10^{6} / \mu \mathrm{L}$ and $13.36 \pm 1.3$ vs $\left.11.85 \pm 1.2 \mathrm{~g} / \mathrm{L} ; \mathrm{p}<0.05\right)$. MCHC and platelet were also not elevated in metabolic syndrome than in control rats respectively $(31.5 \pm 8.2$ vs $45.3 \pm 10.4$ and $356.6 \pm 92.2 \mathrm{~g} / \mathrm{dl}$ vs $\left.485.2 \pm 89.4 \times 10^{6} \mu \mathrm{L} ; \mathrm{p}<0.05\right)$. However, erythrocyte indices as MCV didn't showed statistically significant variations among the LF and control rats $(56.08 \pm 2.01$ vs $55.4 \pm 2.8 \mathrm{fl} ; \mathrm{p}<0.05)$. MS appeared to significantly decrease to white blood cell concentration, lymphocytes and neutrophils which probably reduced the immune defense mechanism. The findings demonstrated that MS caused significant undesirable alterations in hematological parameters in rats and it possible to suspect a coexistence between anemia and the metabolic syndrome in this animal model. In conclusion, the rats induced fat metabolism syndrome affected hematocrit and hemoglobin levels and it possible to suspect a coexistence between metabolic syndrome and the anemia in this animal model.

Keywords: Hematogical parameters, Fat diet, Metabolism syndrome, Wistar rat
Volume 5 Issue 6 - 2018

Monteomo GF, Kamagate A, Yapo AP
Laboratory of Physiology, Pharmacology and Pharmacopoeia,
UFR-Science of Nature, University in Abidjan, Côte d'lvoire

Correspondence: Monteomo Gnate Francois, Laboratory of Physiology, Pharmacology and Pharmacopoeia, UFR-Science of Nature, University in Abidjan, Côte d'lvoire,

Email monteomo_gnate@yahoo.fr

Received: December 13, 2018 | Published: December 19, 2018

\section{Introduction}

Metabolic syndrome (MS) is a multiplex risk factors for cardiovascular disease and type 2 diabetes mellitus. The defining clinical criteria of MS include central obesity, dyslipidaemia, hypertension and glucose intolerance. ${ }^{1}$ This epidemic affects about $35 \%$ and $50 \%$ of the adult population respectively to United States and Northern Europe. ${ }^{2}$ The prevalence of MS varies by $4.4 \%$ in Côte d'Ivoire. $^{3}$

According to Etim, ${ }^{4}$ the examination of blood provides the opportunity to clinically investigate the nutritional, physiological and pathological status of an individual or an animal. The number of the blood count also called blood count is the most prescribed biological examination for all pathologies. It provides information about blood cells that help maintain the integrity of the body. This examination includes the counting of all cells or figured elements of the blood and studies certain particular parameters of the blood. It is a quantitative and qualitative study that is to say it allows to determine the number of red blood cells accompanied by parameters allowing to characterize the erythrocyte population, leucocytes of blood and the detection of other abnormal cells. Among the erythrocyte indices, the mean corpuscular volume (MCV) which accounts for the size of red blood cells, is a blood parameter thus helps to establish the etiological diagnosis of anemia. MCV defines the size of the red blood cells and the mean corpuscular hemoglobin $(\mathrm{MCH})$ quantifies the amount of hemoglobin per red blood cell. The mean corpuscular hemoglobin concentration (MCHC) indicates the amount of hemoglobin per unit volume. In contrast to $\mathrm{MCH}, \mathrm{MCHC}$ correlates the hemoglobin content with the volume of the cell. ${ }^{5}$ According to the size of the red cell, anemias are classified, as being normocytic (normal MCV), macrocytic (increased $\mathrm{MCV}$ ), or microcytic (decreased MCV) while the MCHC is blood parameters for identifying normo and hypochromic anemias. ${ }^{5}$

The numbers of total leukocytes, neutrophils and lymphocytes were elevated levels increased in accordance with the numbers of delected metabolic components. ${ }^{6}$ Hematocrit (HCT) was reported to be positively associated with insulin resistance, which is the basic pathogenesis for $\mathrm{MS}^{7}$ and elevated erythrocyte parameters were confirmed to be associated with MS or its components, suggesting that erythrocyte parameters might be a potential predictor for risk of MS. ${ }^{8}$

Increasing studies have reported that erythrocyte parameters, including red blood cells (RBCs), haematocrit, haemoglobin ( $\mathrm{Hb}$ ) and red blood cell distribution width (RDW), are associated with metabolic syndrome (MS). A number of these studies have revealed that metabolic syndrome could exert diverse effects on haematological indices of animals. ${ }^{9}$ and humans. ${ }^{10-12}$

Although various cross-sectional studies have shown that erythrocyte parameters, including red blood cell, hemoglobin and hematocrit, were linked with metabolic syndrome (MS), few experimental studies have been used to confirm their relationship. The only the combination of sugar and fat, present in beverage and diet was found to result in the development of metabolic syndrome and liver vascular complications in rats. ${ }^{13}$ 
This work is based on the use of an experimental model of nutritional metabolic syndrome, the Wistar rat is subjected to a normal diet supplemented with low dose of $10 \%$ (LF) and high dose of $30 \%$ (HF) pig fat to follow some changes in hematological parameters.

\section{Material and methodes}

\section{Animal material and livestock}

The experimental protocol consisted of 21 rats mixed in 3 groups of 7, as well as Rattus norvegicus of Wistar strain composed of males and females, of the pet shop of the physiology, pharmacology and pharmacopoeia laboratory of Nangui Abrogoua University, Abidjan. Rats aged 8 to 9 weeks and with a homogeneous mean body weight of $110.60 \pm 7.5 \mathrm{~g}$ are fed with standard diet (FACI ${ }^{\circledR}$, Abidjan, Côte d'Ivoire) for control rat or grains added to $10 \%$ (LF) and $30 \%$ (HF) pig fat for experimental rats for 9 weeks (63 days). The breeding is done in a lighted room 12 hours a day, and whose temperature is kept constant $\left(22\right.$ to $\left.23^{\circ} \mathrm{C}\right)$ in an enclosure equipped with an air conditioner (Smart, Canada). The animals have free access to food and water and are weighed once a weeks.

\section{Blood sampling}

Blood samples were taken in healthy rats on days 0 and apparently healthy at the experience end. The rats are anesthetized with a solution of ether soaked in cotton after 12 hours of fasting. The blood collected by ponctures of the retro-orbital sinus is recovered in EDTA tubes in order to count the number and see the shape of the blood cells the same day of sampling.

\section{Determination of hematological parameters}

The hematological parameters are determined quantitatively automatically by a BC-30s hematology analyzer. This device consists of the main unit, reagents, controls and calibrators. The analyzer uses the electrical impedance method to determine the count and size distribution of RBC, WBC and PLT; it uses the colorimetric method to determine HGB. From the aforementioned data, the analyzer calculates other parameters. ${ }^{14}$

\section{Blood smear}

A droplet of blood is deposited on a glass slide used to prepare the blood smear. Staining allows the identification of leukocytes by their specific characteristics highlighted by a suitable dye. Smear staining was performed with a May-Grunwald-Giesma solution, based on the successive use of two dyes: May-Grunwald and Giesma. The first fixes the smear by its methyl alcohol and colors the acidophilic elements and specific granulations of the leucocytes. The second one colors especially the nuclei and the azurophilous parts. The smear is examined under an optical microscope using the objective (x 100).

\section{Statistical analyses}

The statistical analysis of the data is done with the GraphPad Prism 5.01 software (San Diego, California, USA). Whenever a significant difference $(p<0.05)$ is revealed, the ANOVA test is completed with Tukey's post ANOVA test to identify the variable (s) with very significant differences from the values witnesses (Table 1 ). The difference between two means is considered significant if $\mathrm{p}<0.05$, highly significant (Figure 1).

Table I Means assigned the same letter on the same line are not significantly different at the 0.05 threshold According to the Tukey test. ( $\mathrm{n}=7$ ): number of animals per group; $\mathrm{p}<0.05 ;(*)=$ significant The experimental rats with low dose of $10 \%$ (LF) and high dose of $30 \%$ (HF) pig fat diet were induced metabolic syndrome.

\begin{tabular}{|c|c|c|c|c|c|c|}
\hline \multirow[b]{2}{*}{ Physiological parameters } & \multicolumn{3}{|c|}{ Initial values (0 Week) } & \multicolumn{3}{|c|}{ Final values (9 Weeks) } \\
\hline & Control & $10 \%$ LF & $30 \%$ HF & Control & $10 \%$ LF & $30 \% \mathrm{HF}$ \\
\hline WBC $\left(10^{3} / \mu \mathrm{l}\right)$ & $11.09 \pm 2.4^{a}$ & $11.02 \pm 2.3^{\mathrm{a}}$ & $10.95 \pm 1.9^{\mathrm{a}}$ & $11.3 \pm 2.5^{\mathrm{a}}$ & $15.1 \pm 2.7^{b}$ & $12.1 \pm 2.1^{b}$ \\
\hline $\operatorname{RBC}(\mid 06 / \mu l)$ & $7.67 \pm 2.9^{\mathrm{a}}$ & $7.3 \pm 3.1^{\mathrm{a}}$ & $7.3 \pm 2.8^{\mathrm{a}}$ & $7.086 \pm 3.2^{\mathrm{a}}$ & $6.84 \pm 2.9^{b}$ & $6.63 \pm 2.8^{b}$ \\
\hline $\mathrm{Hb}(\mathrm{g} / \mathrm{dl})$ & $13.2 \pm 1.02^{\mathrm{a}}$ & $12.89 \pm 1.2^{\mathrm{a}}$ & $|2.8 \pm 1.0|^{\mathrm{a}}$ & $13.36 \pm 1.3^{\mathrm{a}}$ & $13.16 \pm 1.5^{\mathrm{a}}$ & $11.8 \pm 1.2^{b}$ \\
\hline HCT (\%) & $37.8 \pm 9.4^{a}$ & $36.95 \pm 9.7^{\mathrm{a}}$ & $36.95 \pm 8.6^{a}$ & $37.2 \pm 10.3^{\mathrm{a}}$ & $33.1 \pm 9.5^{b}$ & $34.5 \pm 8.7^{\mathrm{b}}$ \\
\hline $\mathrm{MCV}(\mathrm{fl})$ & $55.9 \pm 1.9^{a}$ & $54.8 \pm 2.1^{\mathrm{a}}$ & $54.7 \pm 2.06^{a}$ & $56.08 \pm 2.1^{a}$ & $55.2 \pm 2.4^{\mathrm{a}}$ & $55.4 \pm 2.8^{\mathrm{a}}$ \\
\hline $\mathrm{MCH}(\mathrm{pg})$ & $24.7 \pm 9.4^{\mathrm{a}}$ & $24.1 \pm 10.1^{a}$ & $23.8 \pm 9.6^{a}$ & $25.7 \pm 11.7^{\mathrm{a}}$ & $25.1 \pm 10.3^{\mathrm{a}}$ & $17.3 \pm 9.8^{b}$ \\
\hline $\mathrm{MCHC}(\mathrm{g} / \mathrm{dl})$ & $44.8 \pm 9.2^{\mathrm{a}}$ & $45.1 \pm 8.6^{\mathrm{a}}$ & $44.20 \pm 9.5^{\mathrm{a}}$ & $45.3 \pm 10.4^{\mathrm{a}}$ & $44.54 \pm 9.8^{\mathrm{a}}$ & $31.5 \pm 8.2^{\mathrm{b}}$ \\
\hline 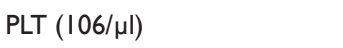 & $358,3 \pm 86^{a}$ & $356,6 \pm 8 I^{a}$ & $359 \pm 86.4^{\mathrm{a}}$ & $356.6 \pm 92.2^{\mathrm{a}}$ & $485.2 \pm 89.4^{b}$ & $294.5 \pm 96^{b}$ \\
\hline NEU (\%) & $1.9 \pm 0.39^{a}$ & $1.95 \pm 0.4^{\mathrm{a}}$ & $1.85 \pm 0.34^{a}$ & $1.8 \pm 0.64^{\mathrm{a}}$ & $1.9 \pm 0.49^{b}$ & $1.02 \pm 0.37^{b}$ \\
\hline LYM (\%) & $7.9 \pm 0.37^{a}$ & $7.2 \pm 0.2^{\mathrm{a}}$ & $7.01 \pm 0.35^{\mathrm{a}}$ & $8.02 \pm 0.28^{\mathrm{a}}$ & $1 \mathrm{I} .4 \pm 0.2^{\mathrm{b}}$ & $8.5 \pm 0.24^{b}$ \\
\hline Mo (\%) & $1.29 \pm 0.6^{\mathrm{a}}$ & I. $19 \pm 0.4^{\mathrm{a}}$ & I. $14 \pm 0.6^{\mathrm{a}}$ & $1.36 \pm 0.89^{a}$ & $1.8 \pm 0.75^{b}$ & $1.55 \pm 0.6^{\mathrm{b}}$ \\
\hline HDL-C,mg/dl & $90.5 \pm 5.4^{a}$ & $78.5 \pm 5.7^{\mathrm{a}}$ & $91.1 \pm 4.8^{\mathrm{a}}$ & $93.5 \pm 4.1^{\mathrm{a}}$ & $61 \pm 4.9^{b}$ & $54.9 \pm 5^{b}$ \\
\hline LDL-C,mg/dl & $92.5 \pm 4.7^{\mathrm{a}}$ & $90.1 \pm 4.1^{\mathrm{a}}$ & $79.5 \pm 4.3^{a}$ & $90.4 \pm 4.2^{\mathrm{a}}$ & $96.4 \pm 9.3^{b}$ & $112.8 \pm 8^{b}$ \\
\hline TG,mg/dl & $134.2 \pm 1.4^{a}$ & $131.5 \pm 1.6^{a}$ & $138 \pm 1.48^{a}$ & $136.2 \pm 4.8^{\mathrm{a}}$ & $142 \pm 5.3^{b}$ & $148.86 \pm 4^{b}$ \\
\hline
\end{tabular}




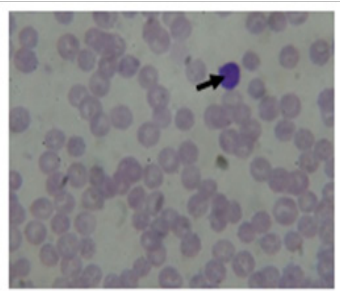

(A)

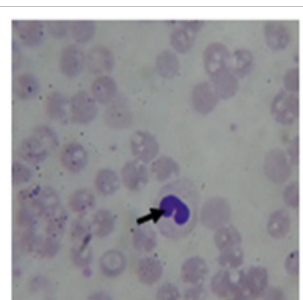

(B)
Figure I Photomicrographs of metabolism syndrome diet of $30 \%$ rats blood showing the presence of Lymphocyte (A) and Monocyte (B). (I0 x; MGG).

The experimental rats with low dose of $10 \%(\mathrm{LF})$ and high dose of $30 \%$ (HF) pig fat diet were induced metabolic syndrome. The Control rats (Control) were fed normal diet. RBC, red blood cell; WBC, White blood cell; Hb, haemoglobin; HCT, haematocrit; PLT, platelet; MCV, Mean Corpuscular volume ; $\mathrm{MCH}$, Mean Corpuscular Hemoglobin; MCHC, Mean Corpuscular Hemoglobin Concentration; Neutrophils, NEU; Lymphocytes, LYM; Monocytes, Mo. HDL-C, high density lipoprotein cholesterol; LDL-C, low density lipoprotein cholesterol; Triglycerides, TG.

\section{Discussion}

For 9 weeks the different diets were followed and at the end of the experiment the blood is taken for cell counting (NFS) and hemoglobin determination. The values of hematocrit (HCT), Red blood cell (RBC) count and hemoglobin concentration significantly decreased in rats metabolic syndrome than in control rats respectively $(37.24 \pm 10.3$ vs $33.16 \pm 9,5 \% ; 7.08 \pm 3.2$ vs $6.63 \pm 2.8 \times 10^{6} / \mu \mathrm{L}$ and $13.36 \pm 1.3$ vs $11.85 \pm 1.2 \mathrm{~g} / \mathrm{L})$ in contrast to the high values of these erythrocyte parameters in clinical cases. ${ }^{15}$ which are $(42.27 \pm 4.09$ vs $40.68 \pm 3.63 \%$; $4.99 \pm 0.8$ vs $4.53 \pm 0.5 \times 10^{2} / \mathrm{L}$ and $147.11 \pm 12.57$ vs $\left.139.02 \pm 12.68 \mathrm{~g} / \mathrm{L}\right)$. In fact, the reduction in erythrocyte parameters observed in our trial could be due to the coexistence metabolic syndrome and anemia in the same individual ${ }^{16}$. Individual with high serum ferritin were found to have higher risk of the metabolic syndrome and combined anaemia and the metabolic syndrome, ${ }^{16}$ this last case is seen in our experience. Other findings, hemoglobin levels was positively associated with MS in animal and human. Young rats with all the symptoms of metabolic syndrome induced by a fat-enriched diet $(60 \% \mathrm{Kcal})$ experienced a significant increase in hemoglobin compared to control rats, ${ }^{9}$ probably due to the absence of anemia. In this last case, association between MS and higher hemoglobin levels in the elderly indicating that current dietetic recommendations. ${ }^{10}$

Platelet count is one of the most important screen tests of platelet function. A decrease in the circulating platelets less than $50 \%$ of the normal value will cause bleeding. ${ }^{17}$ The reduction observed in the platelet counts in HF rats than control rats $(356.6 \pm 92.2$ vs $\left.294,5 \pm 96 \times 10^{6} / \mu 1 ; \mathrm{p}<0.05\right)$ may indicate possible effects on blood clotting in the fat metabolic syndrome rat. However, the increased platelet counts in LF rats than control (240,5 vs and $485.6 \pm 89.4$ vs $294,5 \pm 96 \times 10^{6} / \mu \mathrm{l} ; \mathrm{p}<0.05$ ), high a platelet count sometimes indicated inflammatory or infectious disease and liver disease in this syndrome. ${ }^{1}$

Erythrocyte indices don't define the cause of anemia, but they may be helpful during the diagnostic workup. A significant decrease in the number of red blood cells, MCHC and $\mathrm{MCH}$ is observed with metabolic syndrome HF rats compared to the control respectively $\left(7.08 \pm 3.02\right.$ vs $6.63 \pm 2.8 \times 10^{3} / \mu \mathrm{L} ; 45.3 \pm 10.4$ vs $31.5 \pm 8.2 \mathrm{~g} / \mathrm{dl}$ and
$25.7 \pm 11.7$ vs $17.35 \pm 9.8 \mathrm{pg} ; P<0.05$ ). The $\mathrm{MCV}$ value did not have a significant difference in the whole of the rats and suggesting a hypochromic normocytic anemia in these animals. This result corroborated with that of rats having lower hemoglobin concentration and hematocrit after consuming $(21.1 \%)$ fat diets, ${ }^{19}$ and had similary to iron deficiency aneamia. ${ }^{20}$

The SM led to a significant change in the blood count while the number of leukocytes increased significantly in LF and HF rats than the control rats $(15.14 \pm 2.7$ and $12.18 \pm 2.1$ vs $11.3 \pm 02.5 ; P<0.05)$ at the end of experience. In fact, high WBC count is strongly associated with metabolic syndrome in rat, ${ }^{21}$ and human..$^{22,23}$ White blood cell count was significantly positively correlated with body mass index, the expression of an insulin-resistant state or involvement of the MS (Nakanishi, 2004; Park, 2009). And, an increase in the WBC count with the MS could be due to the presence of lymphocytes and monocytes in this inflammatory reaction (Figs: lymphocyte and Monocyte).

The increase in leukocytes can be characterized by an increase in the number of monocytes in HF rats compared to controls (1.36 \pm 0.89 vs $1.55 \pm 0.64 ; \mathrm{P}<0.05)$ and lymphocytes in $L F$ rats compared to controls $(8.20 \pm 0.28$ vs $11.4 \pm 0.21 ; \mathrm{P}<0.05)$. Monocytes patrol the circulation in search of diseased or senescent RBC because HFDinduced proinflammatory responses and $\mathrm{RBC}$ alterations. These RBC alteration may be relevant to the mechanisms of atherosclerosis in the setting of metabolism syndrome in mice and human..$^{21,24}$

Neutrophils derived from bone marrow colony-forming unit granulocyte/macrophage progenitors dominate the early stages of inflammation and set the stage for tissue infiltration by macrophages. By contrast with macrophages, neutrophils have classically received only little attention in MS because of low neutrophil count noted in LF rat than the control rat ( $1.8 \pm 0.64$ vs $1.02 \pm 0.37 \%$ ) could be a deterioration of the immune system. In other study of high fructoseinduced MS, significantly increased neutrophil phagocytic activity was observed in early stage of high-fructose diet-induced MS to rats compared with the control group $(154.6 \pm 12.77$ vs $206.5 \pm 14.83$; $P<0.05)$ after activation with opsonized E. coli; the results of this study provide evidence a modification in the production, function of circulating neutrophils and a promotion of their adipose tissue infiltration at an early stage of MS. ${ }^{25}$

In total, an association between inflammation and the metabolic syndrome has been found. ${ }^{26}$ while increase of the WBC, monocytes and neutrophils.

\section{Conclusion}

Changes in hematology parameters in the metabolic syndrome were dominated by hypochromic normocytic anemia corresponding to a decrease in erythrocyte hemoglobin, hematocrit and reticulocyte contents $(\mathrm{MCH}, \mathrm{MCHC})$ and normal value of MCV. This makes it possible to suspect a coexistence between metabolic syndrome and the anemia in this animal model. This anemia seems infectious taking into account the decrease in the number of neutrophils and an increase in lymphocytes and inflammatory based to the presence of monocytes.

\section{Acknowledgments}

The author would like to thank the staff of Laboratory of Physiology, Pharmacology and Pharmacopoeia, NANGUI ABROGOUA University to provide assistance to testing on laboratory animals. 


\section{Conflicts of interest}

The author declares no conflict of interest.

\section{References}

1. Bakker AB, Schaufeli WB, Leiter MP, et al. Work engagement: An emerging concept in occupational health psychology. Work \& Stress 2008;22(3):187-200

2. Gilbukh $\mathrm{Yu} \mathrm{Z}$. Actual problems of validating psychological tests. Questions of psychology. 1978;5:108-118.

3. Greben NF. Psychological tests for professionals. Minsk:Contemporary School. 2007.

4. Bishop S. Develop Your Assertiveness. Kogan Page. 2006.

5. Lounsbury JW, Moffitt L, Gibson LW, et al. An Investigation of Personality Traits in Relation to Job and Career Satisfaction of Information Technology Professionals. Journal of Information Technology. 2016;(1):1-33.

6. Ma Z, Jaeger AM. A Comparative Study of The Influence of Assertiveness on Negotiation Outcomes in Canada and China. Cross Cultura Management: An International Journal. 2010;17(4):333-346.

7. Mitrofan L, Dumitrache SD. Interconnections between Assertiveness and Empathy in Couple Relationships. Journal of Experiential Psychotherapy. 2012;3(59):11-23.

8. Mueen B, Khurshid M, Hassan I. Relationship of Depression and Assertiveness in Normal Population and Depressed Individuals. Internet Journal of Medical Update .2006;2:10-17.

9. Rountree J. Personality Characteristics and Perceptions of Job Satisfaction among Mental Health Professionals. Walden university. 2011

10. Ryan EB, Anas AP, Mays H. Assertiveness by Older Adults with Visual Impairment: Context Matters. Educational erotology. 2008;34:504-515.

11. Salleh A, Zuria M, Amla S. An Investigation of Assertiveness and Satisfaction with Life among Malaysian Secondary School Students. International Journal of Knowledge, Culture and Change Management. 2012;11(6):1-10

12. Sheinov VP. Age and gender factors of assertiveness. System psychology and sociology. 2014;2(10):118-126.

13. Sheinov VP. Assertiveness, internality, affiliation and insecurity of the individual from manipulation: connections and properties. System psychology and sociology. 2015;14(2):107-113.

14. Sheinov VP. Determinants of assertive behavior. Psychological Journal 2015;36(3):28-37.
15. Sheinov VP. Development of the assertiveness test satisfying the requirements of reliability and validity. Questions of psychology. 2014;2:107-116

16. Tanck RH, Robbins PR. Assertiveness, locus of control and coping behaviors to diminish tension. Educational Gerontology. 2008;34:503519.

17. Villa MB, Pereira Del Prette, Zilda Aparecida. Marital Satisfaction: The Role of Social Skills of Husbands and ives. Paidéia. 2013;23(56):379-387.

18. Weiss SE. Negotiators Effectiveness with Mixed Agenda: An Empirical Exploration of Tasks, Decisions and Performance Criteria. Group Decision and Negotiation. 2010;21(3)255-290.

19. Osin EN, Leontiev DA. Approbation of Russian-language versions of two scales of express assessment of subjective well-being.Proceedings of the III All-Russian Sociological Congress. Moscow: Institute of Sociology, Russian Academy of Sciences, Russian Society of Sociologists. 2008.

20. Stolin VV, Romanova TL, Butenko GP. A survey of satisfaction with marriage. Bulletin of Moscow University. Psychology. 1984;14(2):54-60.

21. Fetiskin NP, Kozlov VV, Manuylov GM. Socio-psychological diagnosis of personality development and small groups. Moscow: Publishing house of the Institute of Psychotherapy. 2002:470-473.

22. Ergenel A, Karapinar PB, Camgöz SMN. The effect of assertiveness on conflict handling styles. H.Ü. ktisadi ve dari Bilimler Fakültesi Dergisi. 2011;29(2):69-93.

23. Butt A, Zahid ZM. Effect of Assertiveness Skills on Job Burnout. International Letters of Social and Humanistic Sciences. 2015;63:218-224.

24. Amyaga NV. Methods for measuring personal representation in communication. Journal of practical psychologist. 1998;1:42-53.

25. Great psychological dictionary. Prime-EVROZNAK. 2004.

26. Campbell DT. Recommendations for APA tests standards regarding construct, trait, or discriminant validity. Am Psychologist. 1960;15(8):546-553.

27. Anastasi A, Urbina S. Psychological testing. St. Petersburg: Peter, 2002.

28. Lounsbury JW. Personality Characteristics of Business Majors as Defined by the Big Five and Narrow Personality Traits. Journal of Education for Business. 2009;84(4):200-205.

29. Ikiz FE. Self-perceptions about properties affecting assertiveness of trainee counselors. Social behavior and personality. 2011;39(2):199-206. 